\title{
Erratum to: Distribution, morphological and histochemical characteristics of foliar trichomes of Plectranthus zuluensis (Lamiaceae)
}

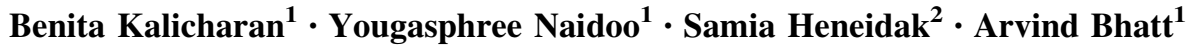

Published online: 28 August 2015

(c) Botanical Society of Sao Paulo 2015

\section{Erratum to: Braz. J. Bot \\ DOI 10.1007/s40415-015-0194-2}

The authors apologize for having overlooked some important revision due to the converting of some figure labels. Please note the following corrections:

Underneath the Results section "Non-glandular trichomes" (Figs. 9, 10) should read (Figs. 8, 10) and in section "Peltate trichomes" (Figs. 18, 19) should read (Figs. 15, 16)
At section "Histochemistry":

1. "Sudan Red" should read "Sudan red"

2. "Sudan Black" should read "Sudan black"

3. (Figs. 33-35, 39-41, 45, 47) should read (Figs. 33-35, 38-40, 43-45)

4. "Ruthenium Red" should read "Ruthenium red"

5. (Figs. 36, 42) should read (Figs. 36, 41, 46)

6. (Figs. 37, 43) should read (Figs. 37, 42, 47)

The online version of the original article can be found under doi:10.1007/s40415-015-0194-2.

Yougasphree Naidoo naidooy1@ukzn.ac.za

$\square$ Samia Heneidak

samya_ibrahim@s-science.suez.edu.eg

1 School of Life Sciences, University of KwaZulu-Natal, P/Bag X54001, Durban 4000, South Africa

2 Botany Department, Faculty of Science, Suez University, Suez, Egypt 